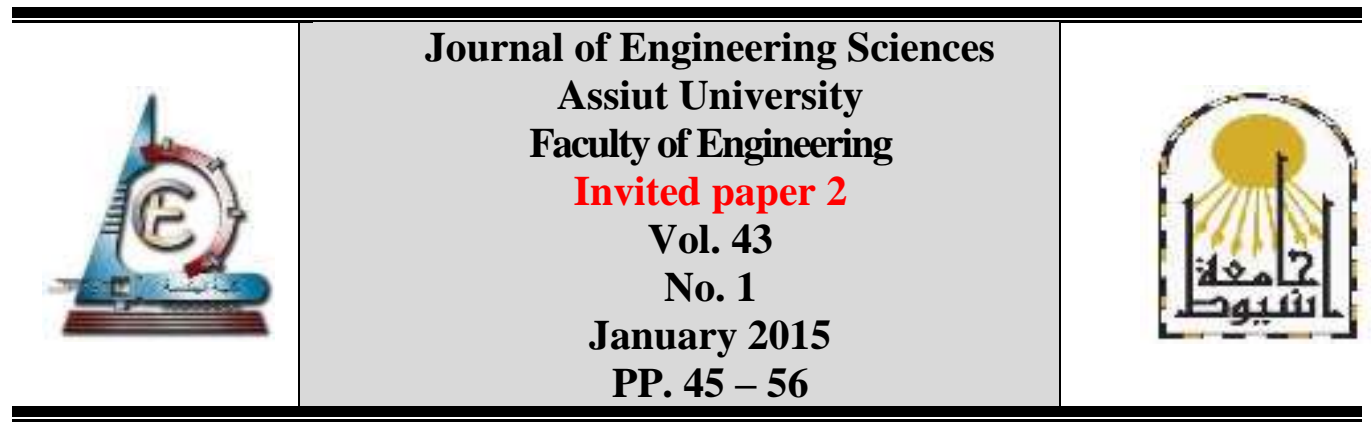

\title{
A NOVEL MULTISTAGE FUZZY CONTROLLER FOR FACTS STABILIZATION SCHEME FOR SMIB AC SYSTEM
}

\author{
Abdel-Fattah Attia ${ }^{1}$ and Adel M. Sharaf ${ }^{2}$ \\ ${ }^{1}$ Kafrelsheikh University, Faculty of Engineering, Dept., of Electrical Eng., Kafrelsheikh, Egypt \\ ${ }^{2}$ Life Senior Member, IEEE, Sharaf Energy Systems, Inc., Fredericton, NB-Canada
}

\begin{abstract}
The paper presents a novel Hybrid-FACTS Based Stabilization Scheme controlled by a hierarchical two-stage fuzzy logic (HFLC)-multi loop dynamic error driven controller. The proposed scheme includes separate Fuzzy control stages for the PD and PID parts to ensure robust and effective dynamic speed control and efficient energy utilization. The PD fuzzy stage used the global error and change of error as the fuzzy input variables. The second stage is the PID-FLC regulation which utilizes the output of the PD-FLC stage and the integral of the global error as input fuzzy variables. The simulation results validate the proposed control scheme effectiveness and robustness with efficient energy utilization, improved power quality and power factor at the Common AC Bus and load bus. A Digital simulation model of the proposed system is developed in Matlab/Simulink/Simpower Software Environment using operational dynamic blocks available in Simulink library.
\end{abstract}

Keywords: Multi-Stage Fuzzy logic dynamic controller; FACTS; Hybrid Switched Capacitive compensator-HSCC; efficient energy utilization, voltage stabilization.

\section{Introduction}

The power quality, Smart Grid Efficient Utilizations and voltage stabilization are now key operational issues. The use of static power converters in electricity has the potential for increasing the capacity of transmission line and improving the supply quality of the electric energy. Flexible AC transmission system (FACTS) devices are used in transmission control whereas custom power devices are used for distribution control. Advantage of modern control systems for switching for modulated filter schemes [1]. A hybrid switched power filter Topology with PWM-switched Strategies is used and validated for energy utilization enhancement, power quality, loss reduction and power factor correction. The hybrid Filtercompensation scheme is suitable in hybrid Renewable Energy-smart grid networks [2-5]. The conventional proportional-integral-derivative (PID) type controller is the best controller used in practice. Because of its simplicity for design and its gain parameters can be tuned manually, using Ziegler-Nichols, analytical methods, Tabu search [6], particle swarm optimization [7],

\footnotetext{
* Corresponding author.

Email address: attiaa1@yahoo.com
} 
Genetic Algorithm [8], pole placement method etc. A hierarchical multi-stage fuzzy logic controller has parallel and series levels where the output of one level becomes the input to the other [13-15]. Typically, pairs of inputs are fuzzified and applied to the rules of the preliminary levels. The outputs of these levels are applied to the rules of subsequent levels of the fuzzy logic system until the result of the final level gives the output of the complete fuzzy logic controller [9].This study introduces a novel Hybrid Series-Parallel Switched Capacitor Compensation (HSCC) is assessed and validated as a tool in improving power quality and efficient energy delivery for a SMIB-AC system [4]. Two proposed dynamic Control schemes are designed using multi-loop dynamic error driven time-descaled and coordinated regulation scheme. The first is PID controller with fixed gains for the regulator. The second is the hierarchical Fuzzy Logic Controller that used the global error and change of error as input variables. A complete simulation model of the proposed system is developed in Matlab/Simulink/Simpower Software Environment using operational dynamic blocks available in Simulink library. This paper is organized as follows. Following introduction, The Hybrid Switched Capacitor Compensation (HSCC) scheme is given. Then the proposed Multi-Tier Fuzzy logic controller is explained. The system simulation with proposed control technique under different operating conditions are preceded the discussion of the results and conclusions.

\section{The hybrid series-parallel switched capacitor compensation (HSCC) scheme}

The configuration of the proposed HSCC scheme is shown in Fig. 1.

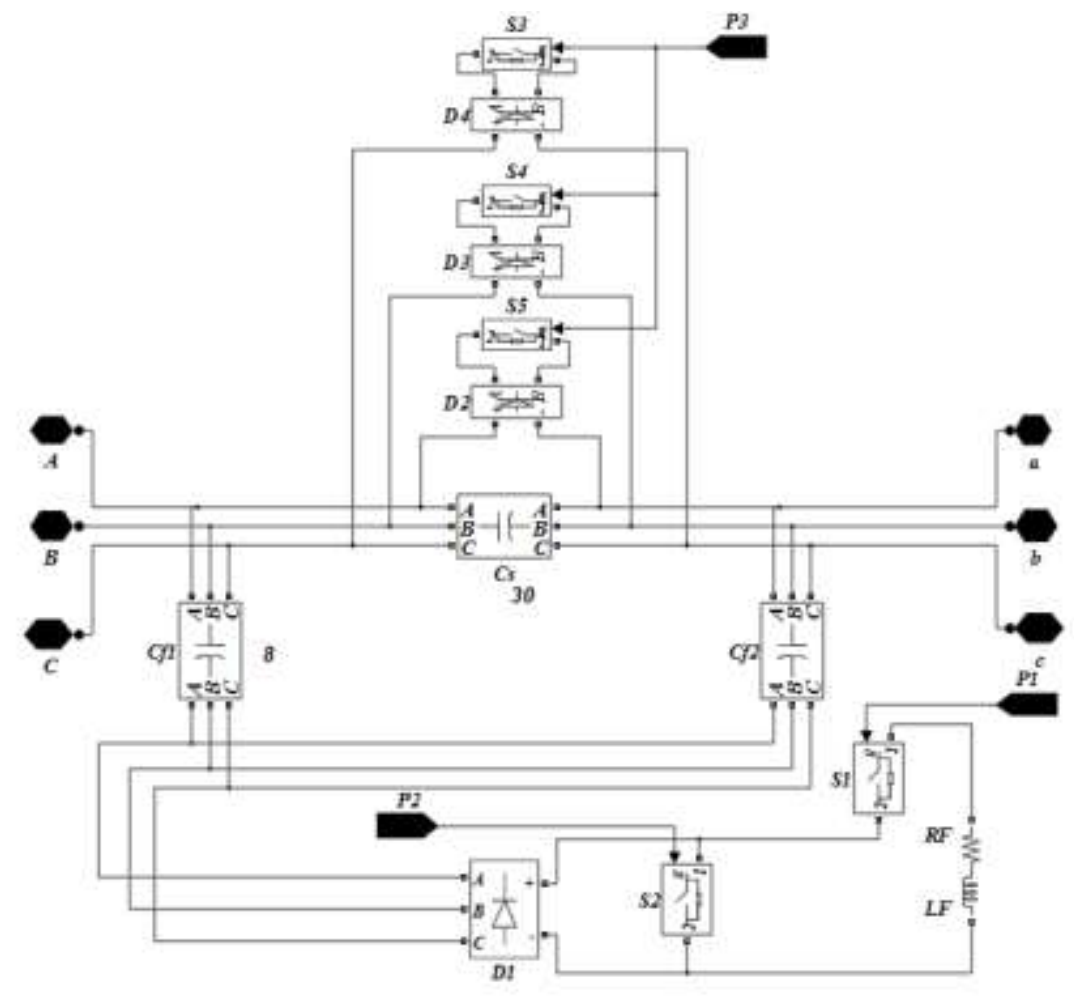

Fig. 1. Hybrid Series-Parallel Switched Capacitor Compensation (HSCC) scheme Located at Feeder Mid-Point.

This device is a switched/modulated hybrid power filter comprising a shunt capacitor bank connected to AC side of a three-arm uncontrolled rectifier in addition to a second 
series switched capacitor bank forming blocking filter. The operational mode of FACTS is defined as follows based on the two controlled signals: Switches S2, S3, S4 and S5 are controlled by PWM pulses through $\mathrm{P} 2$ and $\mathrm{P} 3$. Whereas $\mathrm{S} 1$ is controlled by pulses comes from PWM through P1. The two triggering pulses are complementary with. It means switching of the Parallel Capacitor bank dictates the on/off modes of the series capacitor bank, hence operating as a hybrid switched filter-compensation scheme.

\section{Dynamic error driven control}

The dynamic error driven controller [10-12] is used for the the hybrid FACTS based Device. Three regulation loops are utilized with the first regulator $A$ including three time-descaled weighted loops. The first loop stabilizes the voltage to a specified reference valueand theother two loops are used to dynamically stabilizeCurrent and power sudden changes and excursions.

The minimal ripple content regulator $B$ used to minimizes ripple in the voltage and current waveforms that used in a tri-loop error to mitigate the harmonics. Both regulators utilizes the multi-tier hierarchical fuzzy logic control scheme to ensure a near optimal onoff switching and dynamic pulse width modulation stages as shown in Fig. 2.

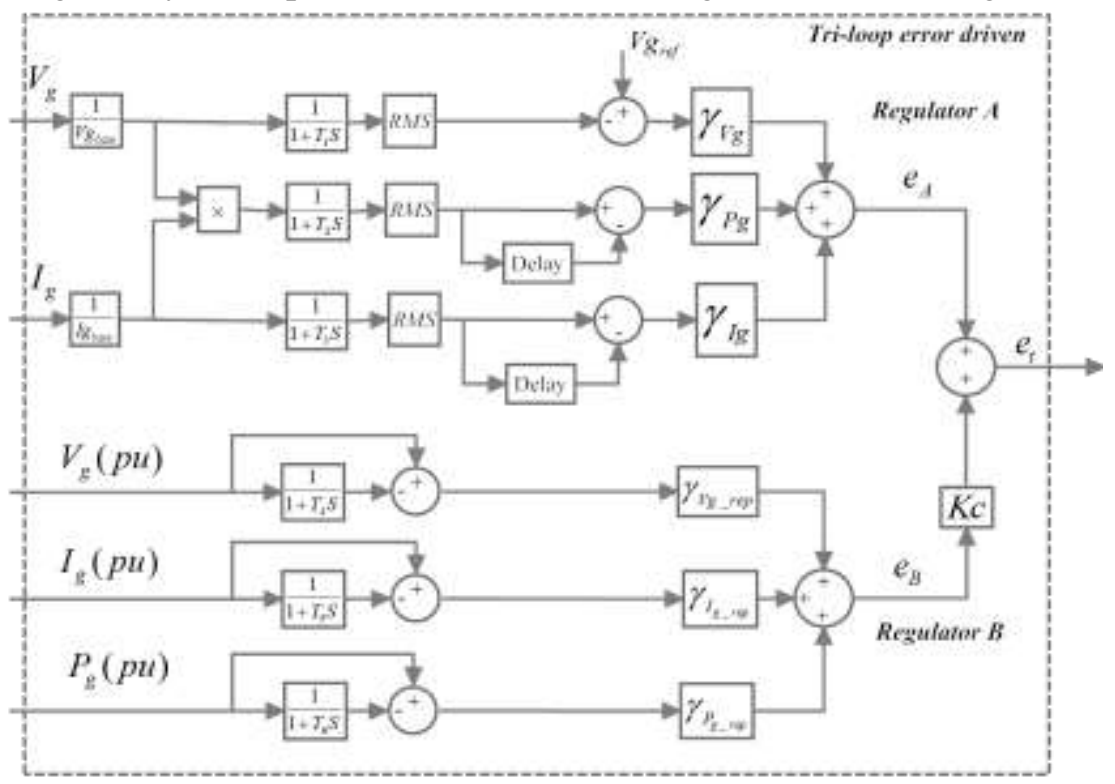

Fig. 2. The Block diagram of the Tri-Loop error driven Controller.

\section{Multi-stage hierarchical fuzzy logic control structure (HFLC)}

The structure of the Two-Stage Hierarchical Fuzzy Logic Two-Stage PID controller has the same effect and equivalent action of a PID controller as shown in Fig 3. Also, the design of the hierarchical fuzzy PID controller begins with the design of a PDFLC to give optimal results. The integral feedback is blended with the fuzzy switch to form the PIDFLC, after the PDFLC is optimized. The first step in the fuzzy controller design is selecting of the input and output variables to represent the (PDFLC). The global error; $e_{t}$ and the rate of change in error $\left(\hat{e}_{t}\right)$ are the input variables to the PDFLC. The next step PIDFLC utilized the output of the PDFLC level and the integral of the position error $\left(\int_{e}\right)$ as an input variable. Each input variables, $\left(e_{t}\right)$ and $\left(\dot{e}_{t}\right)$, for PDFLC is accompanied with a five Gaussian membership functions. The PD value represents the PDFLC output and described 
by a five membership functions. A full rule base, 25 rules, is also defined for PDFLC. The rules have the general form:

If $e_{t}$ is $N S$ and $\dot{e}_{t}$ is $Z$ then $P D$ value is $N S$.

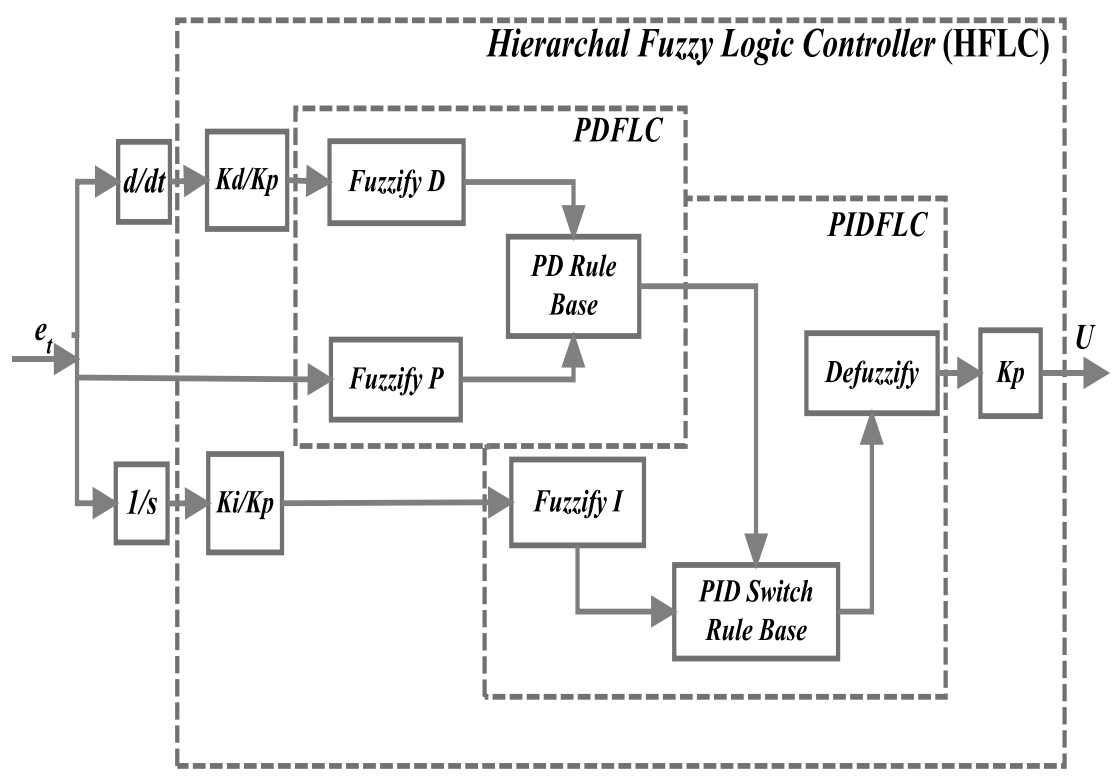

Fig. 3. Two-Level Hierarchal Fuzzy Logic Controller for (HSCC FACTS) energy utilization system.

Where the membership functions $\left(m f_{i}\right)$ is defined as follows: $m f_{j} \in\{N L, N S, Z, P S$ and $P L\}$ However, the output space has 25 different fuzzy sets. The PIDFLC represents the decision maker of the hierarchical fuzzy controller and its structure has two input variables PD value which is the output of PDFLC and the error integrator $\int e_{t}$. The PD input variable accompanied with five fuzzy set, while the second input variable, error integral, is evaluated through three fuzzy set. Therefore, the PIDFLC used a full rule base equal 15 rules. In addition, Fig. 4 and Fig. 5 show the surface rule viewers for the two controllers; PDFLC and PIDFLC respectively. So, the full rules base of the HFLC is 40 rules instead of 125 rules for the classical FLC method used three input variables.

The output signal $(U)$ of the Multi-Tier Hierarchical Fuzzy Logic Control Structure (HFLC) is used to control the switching sequence of the PWM-modulation The on-off switching pattern is dynamically modified based on control signals, hence controlling the two operating modes of the FACTS device as either a Filter or reactive power compensator. A novel fast acting Weighted-Modified PID controller (WMPID) is used [5]. The simulation results compare between the proposed (HFLC) with WMPID controllers for FACTS. 


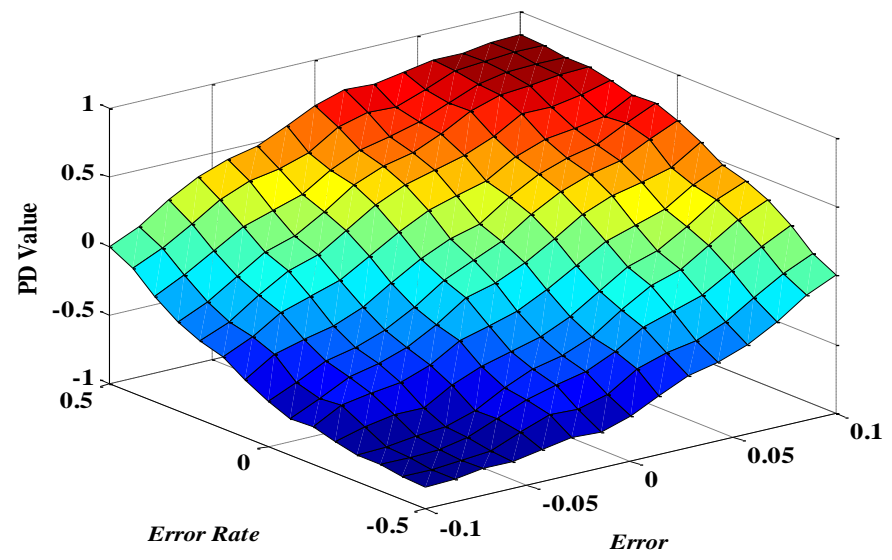

Fig. 4. Rule Assignment Surface viewer of the PDFLC.

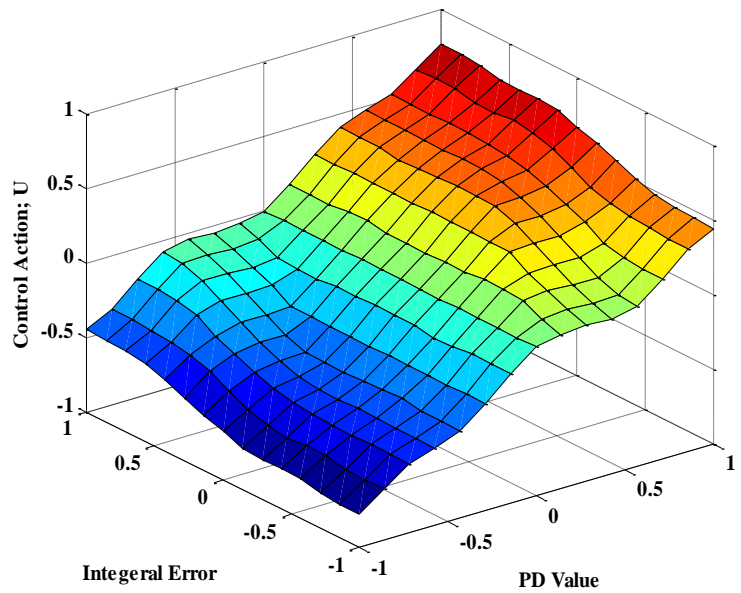

Fig. 5. Rules surface viewer of the PIDFLC.

\section{Digital simulation results and discussions}

The Unified Study AC system configuration is shown in Fig. 6. This system comprises a hybrid AC load of linear, converter type nonlinear and induction motor loads that connected to the load bus as shown in Fig. 7.

\subsection{Normal operations}

Figs. (8-10) illustrate dynamic simulation responses of Power, Power Factor, Reactive Power, RMS Voltage at Load bus in presence of HSCC FACTS controlled by HFLC and PID controllers and without HSCC FACTS under normal operation conditions. 


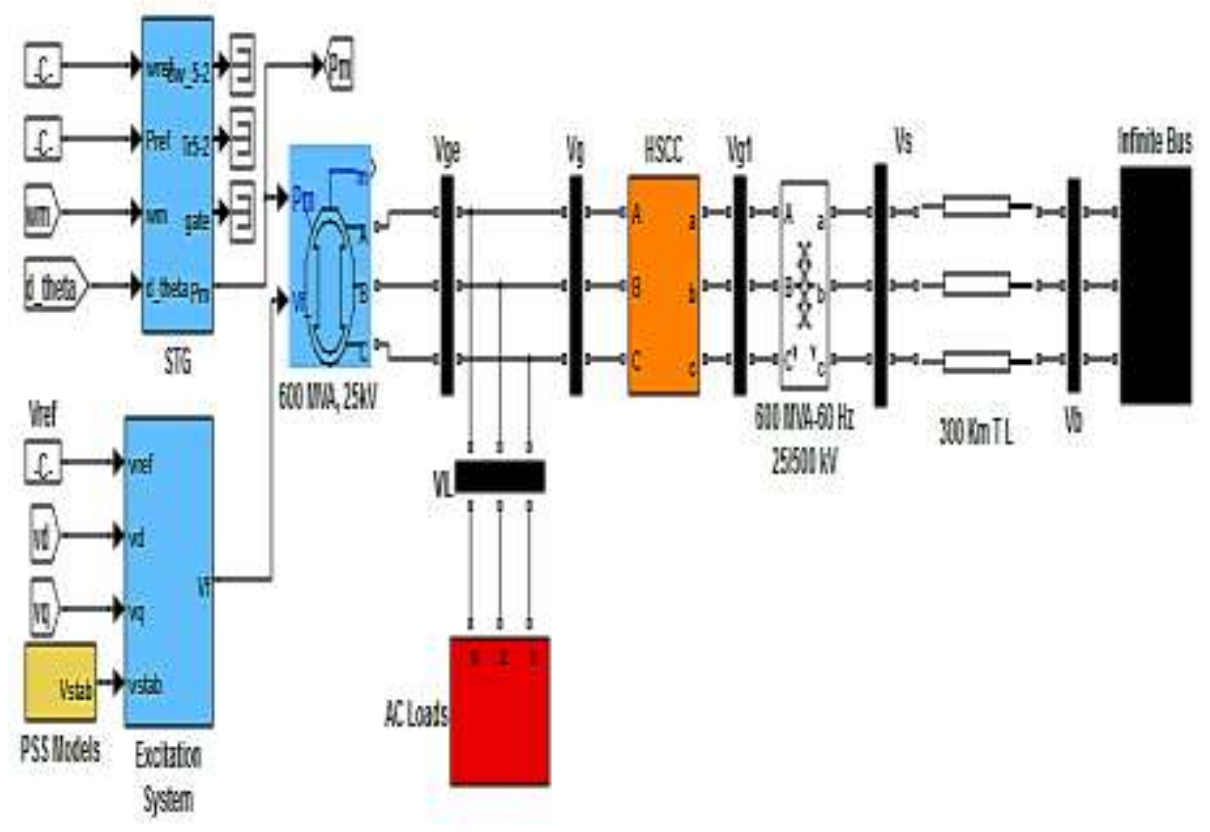

Fig. 6. AC Grid with FACTS-(HSCC) scheme Located at Feeder Mid-Point.

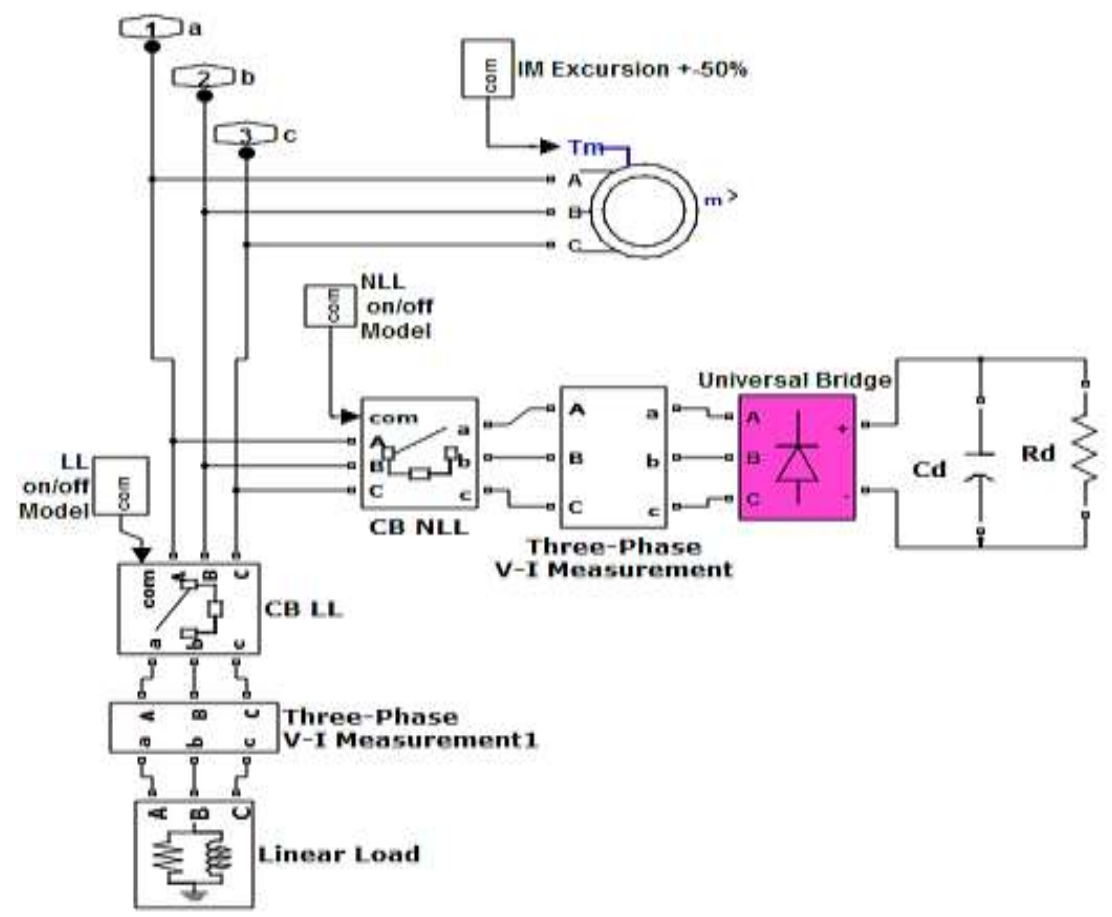

Fig. 7. AC Hybrid Load feed by AC Grid. 

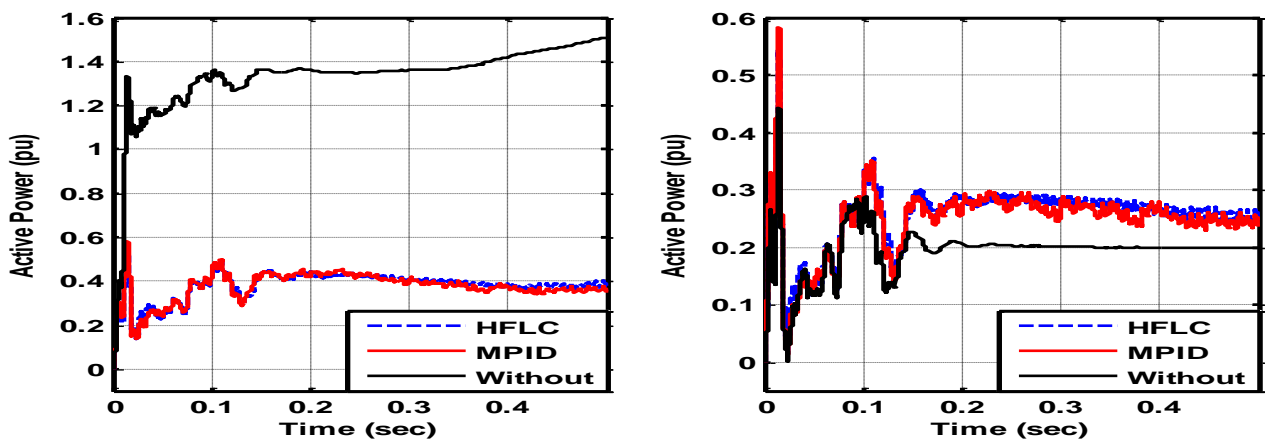

Fig. 8. Active Power at Generator and Load Buses.
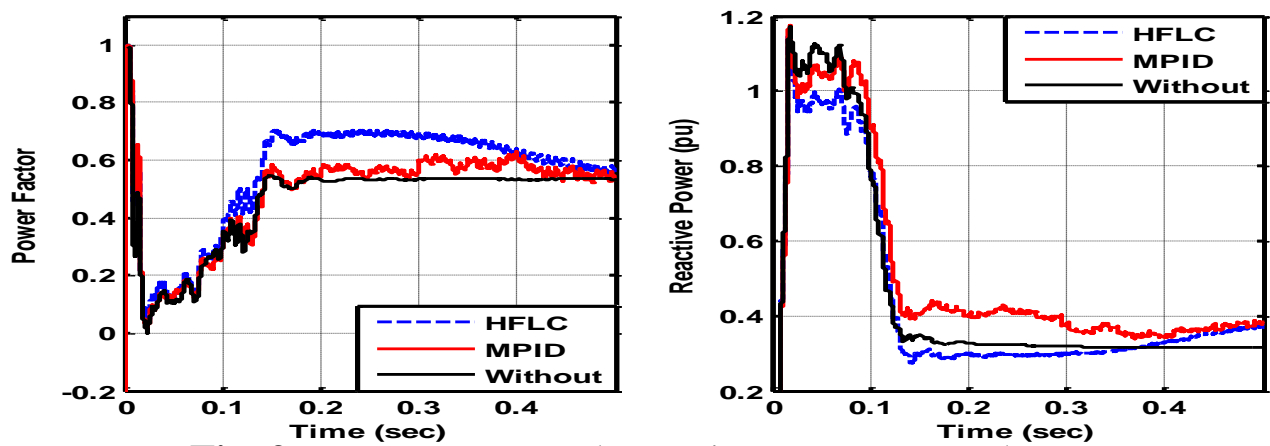

Fig. 9. Power Factor and Reactive power at Load Bus.
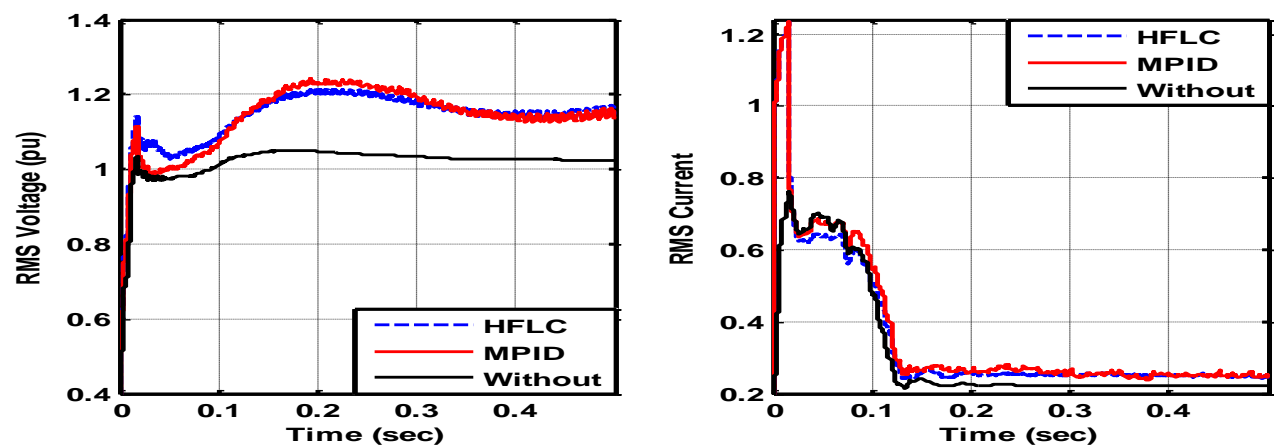

Fig. 10. RMS Voltage and RMS current at Load Buses.

\subsection{Load excursions}

The AC system is examined under load excursion as the following:

Linear load rejected at time $=0.1-0.15 \mathrm{sec}$, Non-Linear load rejected at time $=0.2-0.25$ sec, Motor load Torque; $\mathrm{Tm}$ at $=50 \%$ at time $=0.3-0.35 \mathrm{sec}$ and Motor load Torque; $\mathrm{Tm}$ at $=150 \%$ at time $=0.4-0.45 \mathrm{sec}$. Figs. (11-13) illustrate simulation responses of Power, Power Factor, Reactive Power, RMS-Voltage at Load bus in presence of HSCC FACTS controlled by HFLC and PID controllers and without HSCC FACTS. 
JES, Assiut University, Faculty of Engineering, Vol. 43, No. 1, January 2015, pp. 45 - 56
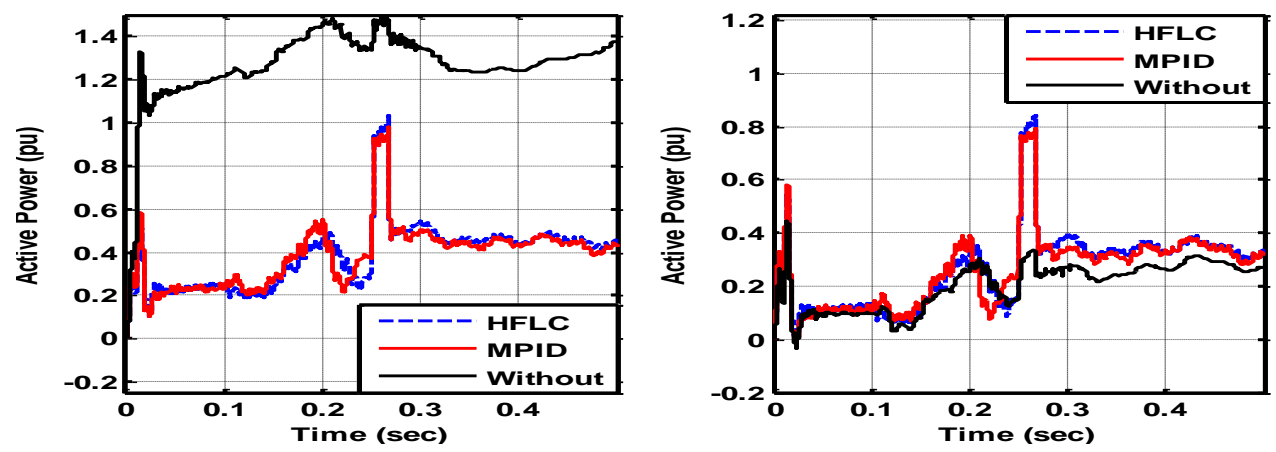

Fig. 11. Active Power at Generator and Load Buses.
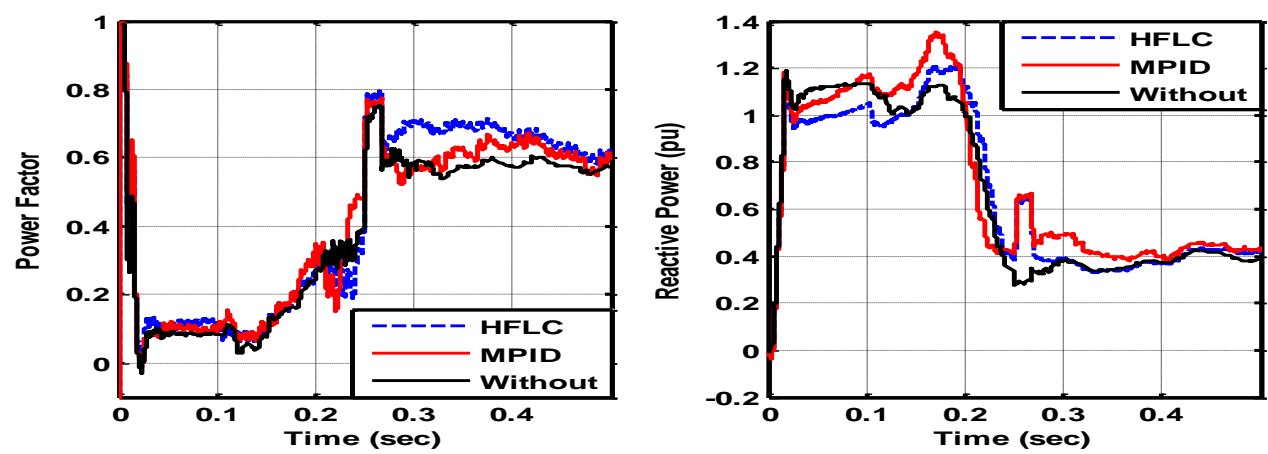

Fig. 12. Power Factor and Reactive power at Load Bus.
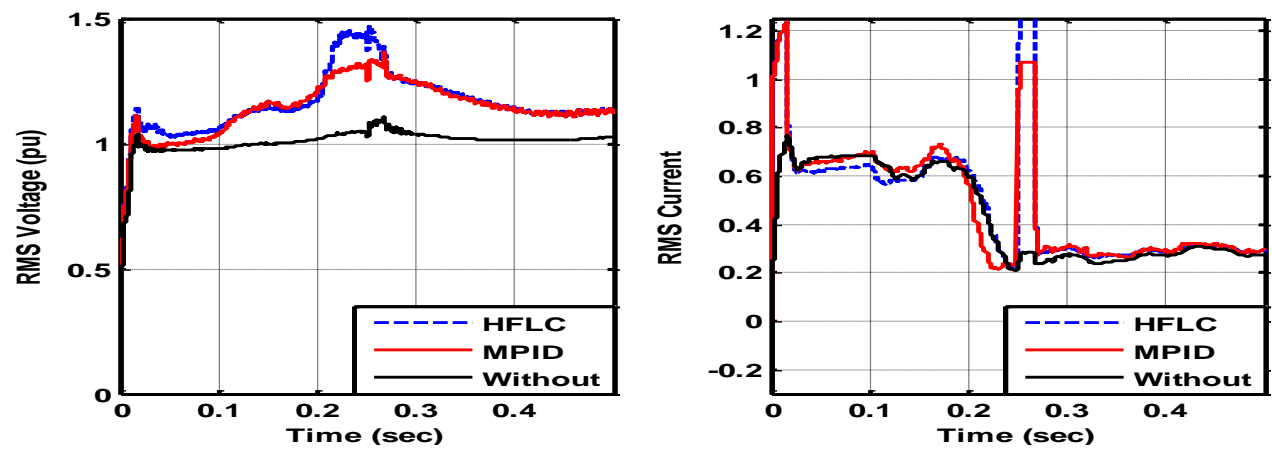

Fig. 13. RMS Voltage and RMS current at Load Buses.

\subsection{Short circuit faults}

The AC system is examined under short circuit fault for time $=0.2-0.3$ at Vs bus. Figs. (14-16) illustrate simulation responses of Power, Power Factor, Reactive Power, RMSVoltage at Load bus in presence of HSCC FACTS controlled by HFLC and PID controllers and without HSCC FACTS. 
Abdel-Fattah Attia ${ }^{l}$ and Adel M. Sharaf, A novel multistage fuzzy controller for facts
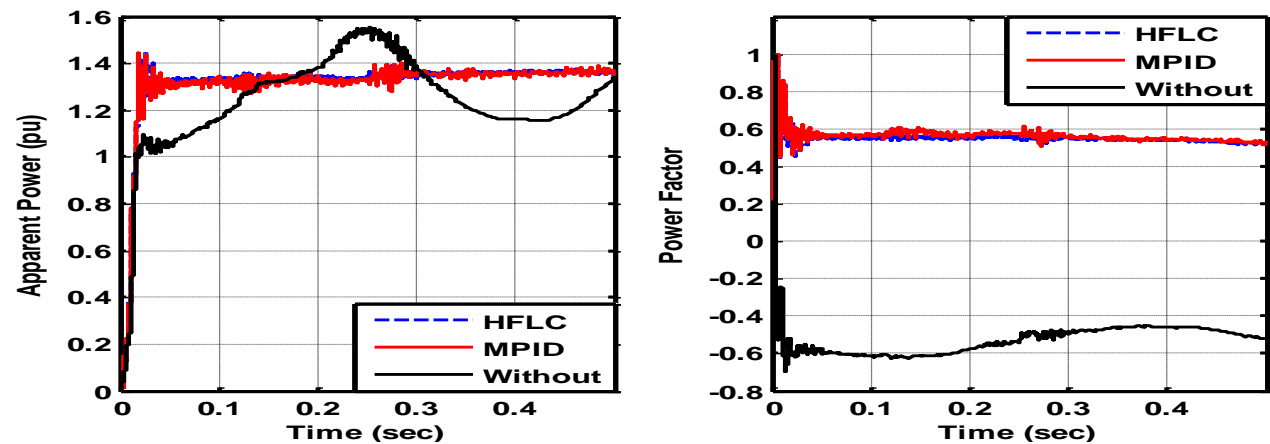

Fig. 14. Active Power at Generator and Load Buses.
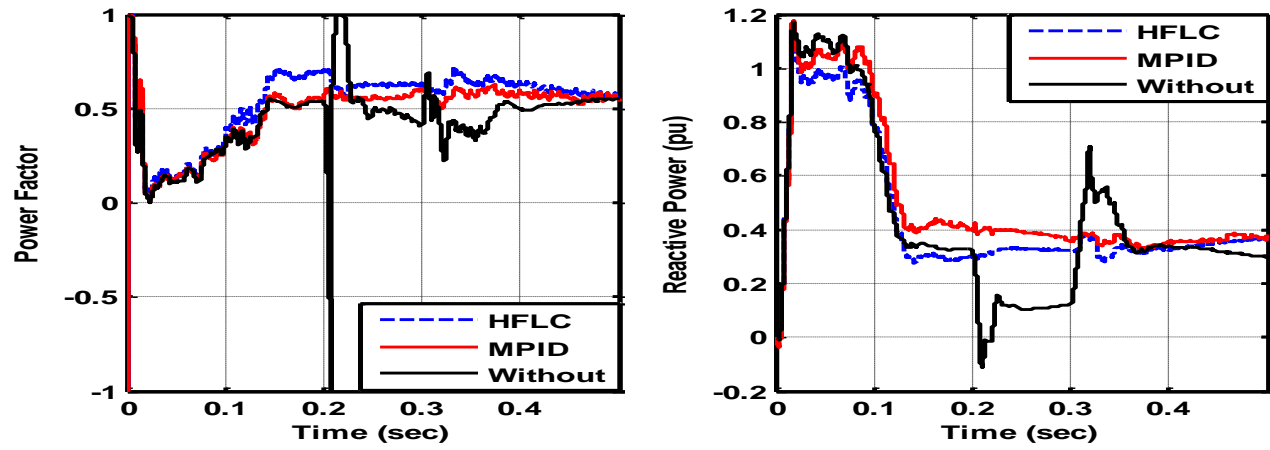

Fig. 15. Power Factor and Reactive power at Load Bus.
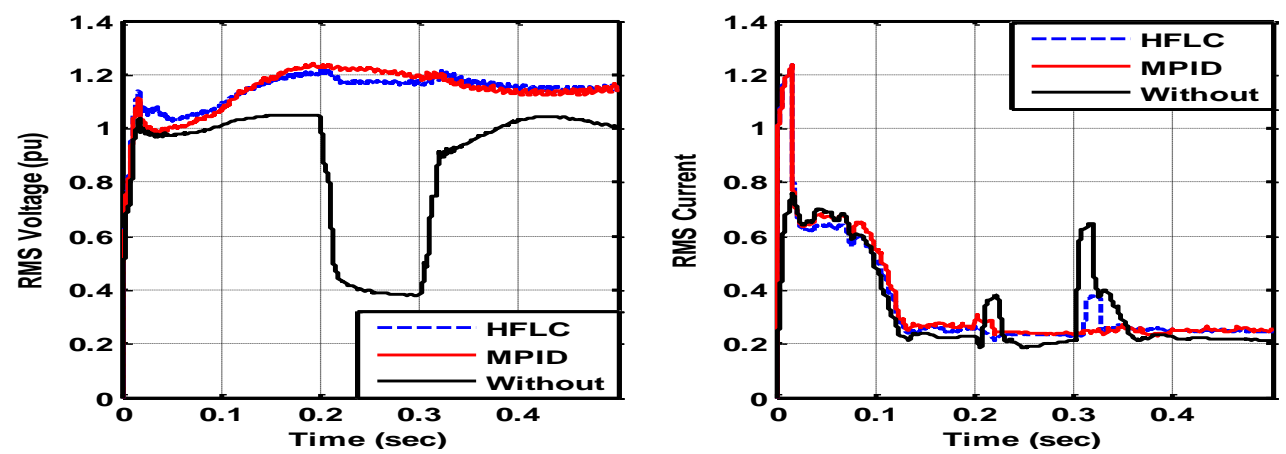

Fig. 16. RMS Voltage and RMS current at Load Buses.

\subsection{Open circuit faults}

The AC system is examined under open circuit fault for time $=0.2-0.3$ at Vs bus. Figs. (17-19) illustrate simulation responses of Power, Power Factor, Reactive Power, RMS Voltage at Load bus in presence of HSCC FACTS controlled by HFLC and PID controllers and without HSCC FACTS. 

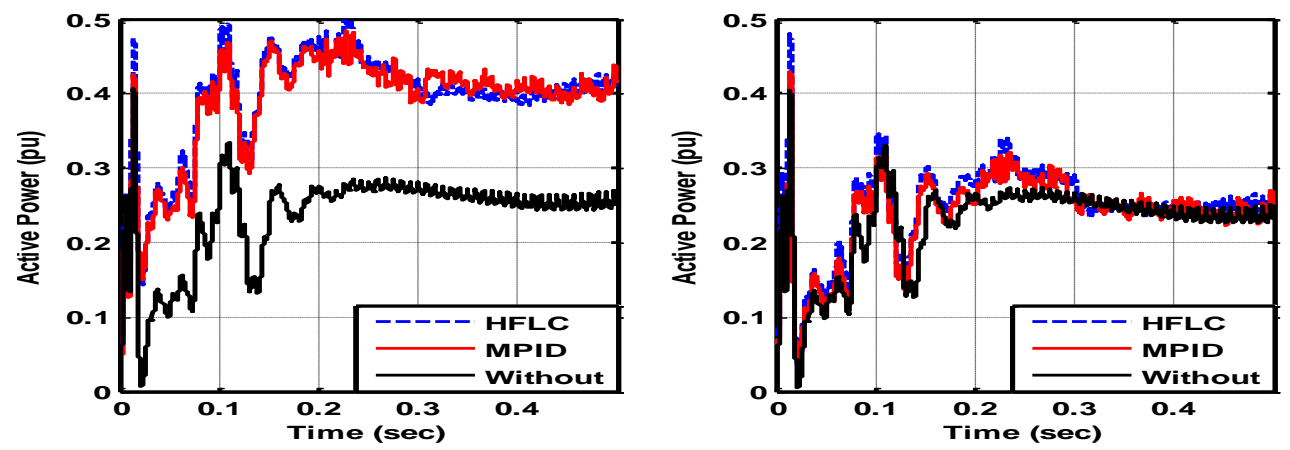

Fig. 17. Active Power at Generator and Load Buses.
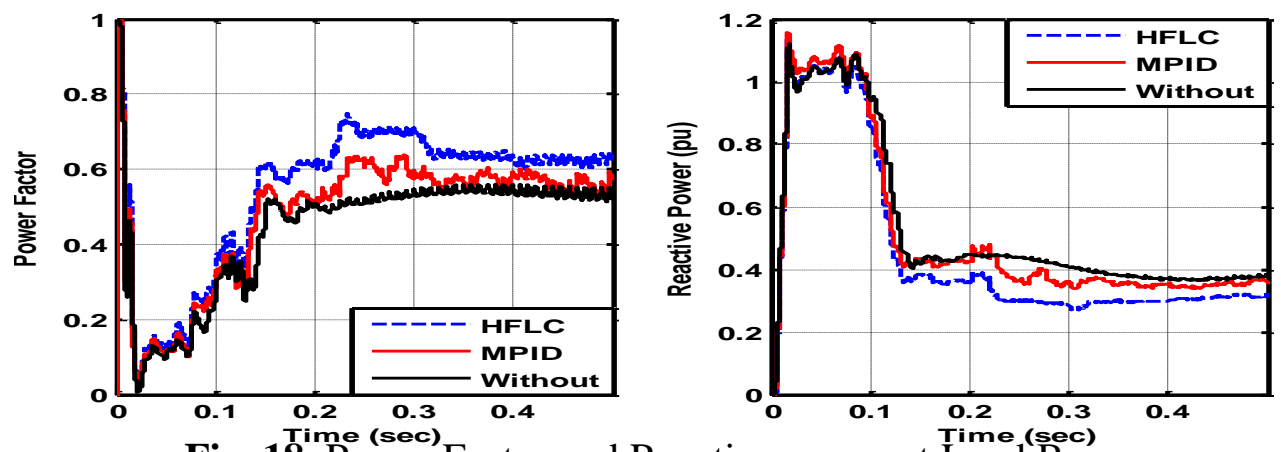

Fig. 18. Power Factor and Reactive power at Load Bus.
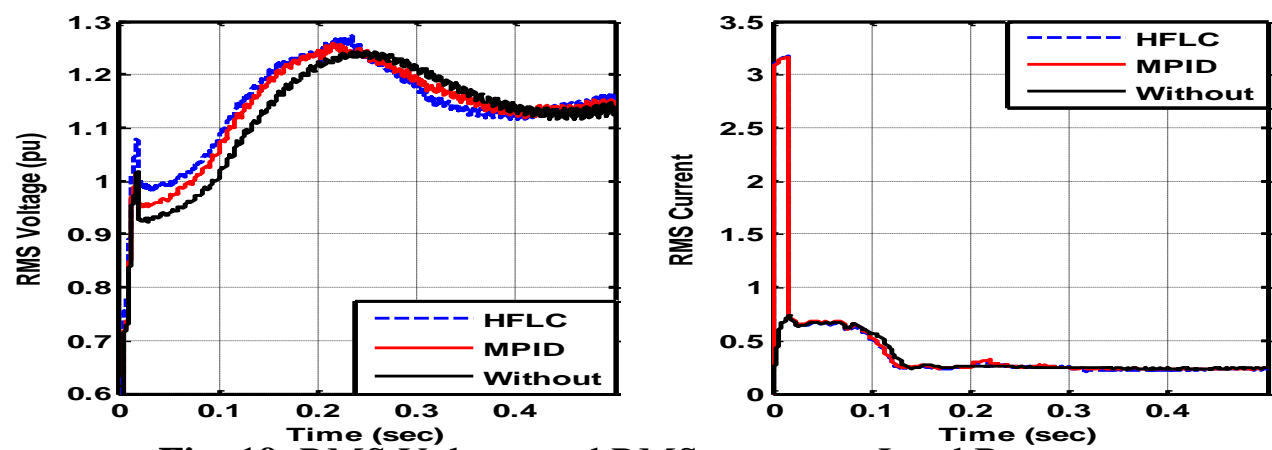

Fig. 19. RMS Voltage and RMS current at Load Buses.

The system dynamic response under open circuit, short circuit and local generator load switching changes for (100-200) milliseconds is generally compared and assessed for ensuring continuous energy delivery over the feeder, reduced feeder losses, enhanced active power delivery and reduced reactive demand on the AC generation. The transient voltages and inrush currents are ensured to be minimum to allow for robust secure operation without damage to FACTS switching devices and series and shunt capacitive banks in comparison to normal operating conditions. The selected excursions and faults duration of few cycles are typical to ensure operation without the activation of protection gear and system isolation. The Performance-Index used is enhanced active power delivery, reduced reactive power demand on the generator, reduced feeder losses and minimum transient over voltages at key generator-system interface bus as well as reduced transient recovery voltages and inrush current conditions on the hybrid FACTS Series and Shunt capacitor banks and switching devices. 


\section{Conclusions}

The paper presents a novel hybrid FACTS Based Voltage stabilization, efficient energy utilization and feeder Loss reduction scheme for smart grid systems. Transient over voltages and inrush currents are also reduced. The two-stage hierarchical fuzzy logic control scheme utilized a tri-regulation multi loop error tracking. The dynamic HFLC controller is utilized to reduce the number of fuzzy rules to a linear function of input variables to allow designing an multi task HFLC control scheme where a global task is divided into sub-levels, hence allowing task-design an independently at each sub-level. A final coordinating strategy is used for optimizing the subtask-controllers to achieve the global tracking/stabilization objective. Digital simulation results validate the proposed control scheme effectiveness and robustness with Efficient Energy Utilization, reduced reactive demand, minimal transient over voltages, reduced inrush conditions, improved power quality and Power Factor at the generator, load and AC system interface Buses. The same FACTS hybrid filter-compensator scheme is now tested for Dynamic Voltage Regulation and Loss reduction in Smart grid distribution and Utilization grid Systems.

\section{APPENDIX}

\begin{tabular}{|c|c|c|c|}
\hline \multirow[t]{2}{*}{ Steam } & \multicolumn{3}{|c|}{ Pout=600MW, Speed $=3600 \mathrm{rpm}$. } \\
\hline & \multicolumn{2}{|c|}{$3 P h ., 2$ poles } & $V g=25 K V(\mathrm{~L}-\mathrm{L}), \mathrm{Sg}=600 \mathrm{MVA}$ \\
\hline \multirow{2}{*}{$\begin{array}{l}\text { Synchronous } \\
\text { Generator: }\end{array}$} & $\mathrm{Xd}=1.79 \mathrm{pu}$ & $\mathrm{Xd}=0.169 \mathrm{pu}$ & $\mathrm{Xd} "=0.135 \mathrm{pu}$ \\
\hline & $\mathrm{Xq}=1.71 \mathrm{pu}$ & $\mathrm{Xq}=0.228 \mathrm{pu}$ & $\mathrm{Xq} "=0.2 \mathrm{pu}$ \\
\hline & \multicolumn{3}{|c|}{$500 \mathrm{KV}(\mathrm{L}-\mathrm{L}), 300 \mathrm{~km}$} \\
\hline Transmission line: & \multicolumn{3}{|c|}{$\mathrm{R} / \mathrm{km}=0.01273 \Omega, \mathrm{L} / \mathrm{km}=0.9337 \mathrm{mH}$} \\
\hline Infinite Bus: & \multicolumn{3}{|l|}{$500 \mathrm{KV}$} \\
\hline HSCC Parameters: & \multicolumn{2}{|c|}{$C_{f 1}=C_{f 2}=250 \mu f$} & $C_{L}=15 \mu f, R_{f}=1.5 \Omega, L_{f}=3 \mathrm{mH}$ \\
\hline SPWM: & \multicolumn{3}{|c|}{$\mathrm{P}_{2}=\mathrm{P}_{3}=\overline{\mathrm{P}_{1}}, \mathrm{Fs} / \mathrm{w}=1750 \mathrm{~Hz}$} \\
\hline \multicolumn{4}{|c|}{ HFLC linguistic variables : $\quad$ Tri-Loop: } \\
\hline mf: membership function. & & $\mathrm{T}_{1}=5 \mathrm{~ms}$ & \\
\hline \multicolumn{2}{|l|}{ NL; Negative Large. } & $\mathrm{T}_{2}=10 \mathrm{~ms}$ & \\
\hline \multicolumn{2}{|l|}{ NS; Negative Small. } & $\mathrm{T}_{3}=5 \mathrm{~ms}$ & \\
\hline \multicolumn{2}{|l|}{ Z; Zero. } & $\mathrm{T}_{4}=20 \mathrm{~ms}$ & \\
\hline \multicolumn{2}{|l|}{ PS; Positive Small. } & $\mathrm{T}_{5}=30 \mathrm{~ms}$ & \\
\hline \multicolumn{2}{|l|}{ PL; Large. } & $\mathrm{T}_{6}=20 \mathrm{~ms}$ & \\
\hline PDFLC & PIDFLC & Delay $=5-10 \mathrm{~ms}$ & \\
\hline \multirow{8}{*}{$\begin{array}{l}\text { Input variables: } \\
\text { Global error }\left(e_{t}\right) \text { and } \\
\text { change of error }\left(\dot{e}_{t}\right) \text {. } \\
\text { Output variable: } \\
\text { PD value. }\end{array}$} & Input & $\gamma_{V g}=1$ & \\
\hline & variables: & $\gamma_{P g}=0.25$ & \\
\hline & PD valueand & $\gamma_{I_{g}}=0.5$ & \\
\hline & the error & $\gamma_{V g-\text { rep }}=1$ & \\
\hline & integrator $\int e_{t}$. & $\gamma_{P g_{-} \text {rep }}=1$ & \\
\hline & $\begin{array}{l}\text { Output } \\
\text { variable: }\end{array}$ & $\begin{array}{l}\gamma_{I g-\text { rep }} \\
K_{c=1}\end{array}$ & \\
\hline & The output & Controller gains & \\
\hline & signal $(U)$ & $\begin{array}{l}\mathrm{Kp}=0-15, \mathrm{Ki}=0- \\
\mathrm{Kd}=0-1, \mathrm{Ke}=0-1\end{array}$ & \\
\hline
\end{tabular}




\section{REFERENCES}

[1] Chandra, B. Singh, B.N. Singh, K. Al-Haddad, "An Improved Control Algorithm of Shunt Active Filter for Voltage Regulation, Harmonic Elimination, Power Factor Correction, and Balancing of Nonlinear Loads", IEEE Trans. on Power Electronics, Vol. 15, No. 3, May 2000, pp.495-507.

[2] A. M. Sharaf, and G. Wang, "Wind Energy System Voltage and Energy Enhancement using Low Cost Dynamic Capacitor Compensation Scheme." Proceedings of the IEEE International Conference on Electrical, Electronic and Computer Engineering. pp. 804-807, 5-7 Sept. 2004.

[3] A. M. Sharaf and K. M. Abo-Al-Ez, "A FACTS based dynamic capacitor scheme for voltage compensation and power quality enhancement," 2006 IEEE International Symposium on Industrial Electronics, vol. 2, pp. 1200-1205, 2006.

[4] A. M. Sharaf, B., Khaki, "A FACTS based switched capacitor compensation scheme for smart grid applications", Innovations in Intelligent Systems and Applications (INISTA), 2012 International Symposium on, page(s): $1-5$.

[5] A. M. Sharaf and R. Chhetri, "A novel dynamic capacitor compensator/green plug scheme for 3-phase 4-wire utilization loads," Canadian Conference on Electrical and Computer Engineering, 2006, CCECE '06, pp. 454-459, 2006.

[6] A. Bagis "Tabu search algorithm based PID controller tuning for desired system specifications." Journal of the Franklin Institute, 348 (2011), pp. 2795-2812

[7] Z. L. Gaing, "A Particle Swarm Optimization Approach for Optimum Design of PID Controller in AYR System", IEEE T ENERGY CONVER, Vol.9 (2), Jun. 2004, pp.: 384391.

[8] A. -F. Attia, H. Soliman, and M. Sabry. "Genetic Algorithm Based Control System Design of a Self-Excited Induction Generator." Acta Polytechnica 46 (2), 11-22, 2006.

[9] A. -F. Attia, "Hierarchical fuzzy controllers for an astronomical telescope tracking." APPL SOFT COMPUT. 9.1 (2009): 135-141.

[10] A. M. Sharaf, R. Chhetri, "A novel dynamic capacitor compensator/green plug scheme for 3-phase 4-wire utilization loads", IEEE-CCECE, Ottawa, Ontario, Canada 2006.

[11] A. M. Sharaf, A. Aljankawey and I. H. Altas "A novel voltage stabilization control Scheme for stand-alone wind energy conversion systems", Proc. Conf. Clean Elect. Power, ICCEP2007, pp.514 -519, 2007.

[12] A. M. Sharaf, M.Z El-Sadek, F.N Abd-Elbar, A.M Hemeida. "A global dynamic error driven control scheme for static VAR compensators." EPSR, 51 (2), 131-141, 1999.

[13] F.L. Chung, J.C. Duan, On multistage fuzzy neural network modeling, IEEE Trans. Fuzzy Syst. 8 (2) (2000) 125-142.

[14] J. M. Adams, K. S. Rattan, "Intelligent control of a direct-drive robot using multi-stage fuzzy logic", Proc. of the 44th IEEE Midwest Symposium on Circuits and Systems, Vol.2, 2001, pp.543-546

[15] H. P. Chen and T. M. Pamg "A new approach of multistage fuzzy logic inference", Fuzzy Sets and Systems, vol. 78, pp.51 -72, 1996. 